\title{
A NEW METHOD OF DETERMINATION OF PHASES AND SYMMETRY IN STAND-TO-SIT-TO-STAND MOVEMENT
}

\author{
MICHALINA BŁAŻKIEWICZ ${ }^{1}$, IDA WISZOMIRSKA ${ }^{1,2}$, and ANDRZEJ WIT ${ }^{1,2}$ \\ ${ }^{1}$ Józef Piłsudski University of Physical Education in Warsaw, Warszawa, Poland \\ Department of Physiotherapy \\ ${ }^{2}$ Almamer University of Economics, Warszawa, Poland \\ Department of Health Protection
}

\begin{abstract}
Objectives: Determination of the phases in a stand-to-sit-to-stand task based on a derivative of the parameter with the lowest variance calculated based on the modified symmetry index. Material and Methods: The study group comprised 11 healthy women and 11 healthy men from the University of Physical Education in Warsaw. The examination of the kinematic and kinetic parameters of sitting down and standing up from a chair was carried out using the Vicon Mx system and Kistler force platforms. Results: The modified symmetry index was employed to select the parameters used to choose those with the lowest variance. Consequently, the phases in a stand-to-sit-to-stand task were determined. Conclusions: It was demonstrated that the task of sitting down is a reverse task with respect to standing up in terms of the symmetry of the parameters analyzed.
\end{abstract}

Key words:

Sit, Stand, Symmetry, Healthy young people

\section{INTRODUCTION}

Similarly to gait, sitting down and standing up from the chair are fundamental human activities. Proper sitting down and standing up habits are developed through situp exercises, which are an integral part of training and conditioning programs in sports and fitness, and are also commonly prescribed in knee rehabilitation settings. Structural disturbances and improper technique of sitting might lead to overload of articular-ligamentous apparatus in lower limbs, with particular focus on knee joints [1]. Improper habits in this function acquired in the childhood and repeated for many years, combined with the weakness of the extensor muscles of the knees and the hips might consequently lead to a number of unfavorable modifications in human motion system. Gradually, more substantial difficulties in performing the sitting down and standing up tasks are observed with age, which induces higher probability of falling down and generates the increased risk of becoming dependent on other people. For this reason, the way the sitting down and standing up are performed is often the focus of diagnostic surveys. It should be emphasized that 1 of the criteria of the properly performed

This work was financially supported by the Grant No. PB-73 (NCN 2011/01/D/NZ7/05296) Mathematical modeling of compensatory functions of lower limb muscles during normal and pathological gait. Grant manager: Michalina Błażkiewicz, PhD.

Received: July 29, 2013. Accepted: April 14, 2014.

Corresponding author: M. Błażkiewicz, Józef Piłsudski University of Physical Education in Warsaw, Department of Physiotherapy, Marymoncka 34, 01-813 Warszawa, Poland (e-mail: michalinablazkiewicz@gmail.com). 
movement of sitting down and standing up is the symmetry of lower limbs.

Rising to stand from a chair has generally been assumed to be a symmetrical activity occurring in the sagittal plane [2]. Some studies report no significant differences between the right and the left side as for vertical ground reaction forces, lower limb joint moments and angular displacements [3], while other record significant asymmetries in the same parameters [4]. Enhanced symmetry during functional tasks is important because the subjects can overload 1 side [5]. Therefore, it seems necessary to identify the kinematic and kinetic parameters during the sitting down and standing up movements in order to find the proper symmetric body movement that minimizes overload in lower limbs when performing this activity.

For the purposes of the biomechanical analysis and optimization of the methods of habits development, phases in many movement activities have been widely discussed. For instance, 4 phases can be observed in a ballistic motion of shot put: preparation, glide, transfer and release [6]. In javelin throw the recorded phases include approach run and the delivery, also called the final thrust or launch phase [7] and, in hand ball, there are phases of arm swing and ball throwing [8]. In cyclic movements, such as human gait, the phases of single and double support and the phase of transfer are observed when walking and the phases of single support and flight are observed when running [9].

One of the problems the authors experienced during the analysis of the stand-to-sit-to-stand motion is the lack of an accurate algorithm in the available literature that would allow for the division of the motion into phases, similar to those defined for instance for free human gait. Previous analyses of the kinematic and kinetic parameters and the symmetry indices calculated for these parameters did not allow for finding an accurate algorithm which would help define the phases based on the changes in only 1 of them. Therefore, the aim of the present study was determination of the phases in a stand-to-sit task based on a derivative of the parameter with the lowest variance calculated on the basis of the modified symmetry index.

\section{MATERIAL AND METHODS}

The study group was composed of 22 healthy students of the University of Physical Education; all of whom were aged 22 years. The group included 11 women (mean body height: $1.68 \pm 0.04 \mathrm{~m}$, range: $1.60-1.77$; body mass: $58.1 \pm 5.6 \mathrm{~kg}$, range: $50-69)$ and 11 men (mean body height: $1.83 \pm 0.07 \mathrm{~m}$, range: $1.68-1.91$; body mass: $75.5 \pm 6.9 \mathrm{~kg}$, range: $59-84$ ).

The measurement of the kinematic and kinetic parameters of the analyzed motion was carried out using Vicon $\mathrm{Mx}$ system (Oxford, UK), consisting of eight cameras with the frequency of recording of $100 \mathrm{~Hz}$, integrated with 2 Kistler (Winterthur, Switzerland) force platforms $(100 \mathrm{~Hz})$. Thirtyfour markers were placed on the body of each subject according to the PlugInGait-FullBody (SACR) standards available within Vicon Mx system. Each subject performed a natural motion of sitting down and standing up from the chair with the dimension of: WDH 44/51/77 cm. The chair did not have any back and arm support. The phase of free sitting on the chair lasted for about $3 \mathrm{~s}$. Each person performed the test 3 times and the analysis was carried out based on the attempts without any random mistakes, with the individuals performing the task naturally.

\section{ETHICS}

Before the measurement, the participants were informed about the study aim, the procedures and the possibility of stopping the experiment at any moment and gave their consent to participate in the experiments. All participants signed an informed consent forms before participation, in accordance with the guidelines of the University's Institutional Review Board. 


\section{STATISTICS}

\section{Kinematics and kinetics parameters}

A detailed motion analysis focused on the 3 components of ground reaction forces normalized for body weight, angles in lower limb joints in 3 planes and the muscle torques normalized for body mass. For each of the parameters analyzed, the minimum and maximum values were determined, with the means that represented the limits for the parameters of healthy subjects.

\section{Symmetry calculation method}

The following variables (v) were considered for the calculations for each of the subjects: angles and muscle torques in the ankle joint, knee joint and hip joint, and ground reaction forces. Each variable was analyzed in 3 planes (p). A modified symmetry calculation index was also proposed. Partial symmetry indices $\left(\mathrm{SI}_{\mathrm{i}}\right)$ were calculated for each of the parameters, at each i point of motion recording, according to the following formula:

$$
\mathrm{SI}_{\mathrm{i}}=\left|2 \times\left(\frac{\left|\mathrm{L}_{\mathrm{i}}\right|-\left|\mathrm{R}_{\mathrm{i}}\right|}{\left|\mathrm{L}_{\mathrm{i}}\right|+\left|\mathrm{R}_{\mathrm{i}}\right|}\right)\right|
$$

where:

$\mathrm{L}, \mathrm{R}$ - data for the left and right lower limb, respectively, i-frame number.

With these partial symmetry indices $\left(\mathrm{SI}_{\mathrm{j}}\right)$, the general indices were calculated for each variable (angle, torque, ground reaction forces), each joint (ankle, knee, hip), and each plane (sagittal, coronal, transverse), according to the following equation:

$$
\mathrm{SI}_{\text {joint,v }}^{\mathrm{p}}=\frac{\mathrm{SI}_{1}+\ldots+\mathrm{SI}_{\mathrm{i}}}{\mathrm{i}}
$$

where:

i - number of frames for a test,

p - sagittal, coronal or transverse plane,

$\mathrm{v}$ - variable: angle, torque or ground reaction forces; therefore,

21 general symmetry indices $\mathrm{SI}_{\text {joint, }}^{\mathrm{p}}$ were obtained for each person.
An additional SImod index was also calculated in order to carry out detailed comparative analyses. The index was the mean of general symmetry indices calculated for a particular variable in a particular joint:

$$
\operatorname{SImod}=\frac{\mathrm{SI}_{\text {joint }, \mathrm{v}}^{\mathrm{sagital}}+\mathrm{SI}_{\text {joint, } \mathrm{v}}^{\mathrm{front}}+\mathrm{SI}_{\text {joint }, \mathrm{v}}^{\text {transerse }}}{3}
$$

Therefore, seven SImod symmetry indices were obtained for each person.

\section{Method of identification of the phases \\ in the stand-to-sit-to-stand task}

The authors' own method was developed in order to determine the phases in the stand-to-sit-to-stand task. The first step consisted in calculation of the variance for the overall symmetry indices. The parameter that was characterized by the lowest variance calculated for symmetry indices $\mathrm{SS}_{\text {joint.v }}^{\mathrm{p}}$ (bending and extension in the hip joint) was taken into consideration. A derivative was calculated for this parameter, thus obtaining an angular velocity curve. Local minimums and maximums constituted the limits for the phases in the analyzed motion.

The stages in the determination of the limits were as follows:

1. In the whole domain of motion, the extreme values for the function of angular velocity in the hip joint: maximum $-\mathrm{v}_{1}{ }^{\text {max }}$ and minimum $-\mathrm{v}_{2}{ }^{\mathrm{min}}$ were found.

2. Within the range of $\left(\mathrm{v}_{1}{ }^{\max }, \mathrm{v}_{2}{ }^{\mathrm{min}}\right)$, the values of local extremes: local maximum $-\mathrm{v}_{2}{ }^{\text {max }}$ and local minimum $\mathrm{V}_{1}{ }^{\text {min }}$ were determined, assuming that curve $\mathrm{f}$ with the values in the ordered set, defined on the topological space, has a local minimum (maximum) in the point $x_{0}$ of this space if there is an open neighborhood $\mathrm{U}$ of the point $x_{0}$ so that for each $x \in U f(x) \leq(\geq) f\left(x_{0}\right)$.

\section{Dynamic symmetry index in the stand-to-sit-to-stand task} In order to determine the dynamics of changes in the symmetry of the parameters analyzed for the phases of motion, a dynamic symmetry index was introduced, calculated as: 


$$
\operatorname{DSI}(\mathrm{t})=\left|\frac{\mathrm{d}\left(\mathrm{SI}_{\text {joint,v }}^{\mathrm{p}}\right)}{\mathrm{dt}}\right|
$$

where:

$\mathrm{t}$ - time.

The above-described index was calculated for all the parameters, whereas most of the information was provided by the analysis of the dynamics of changes in the symmetry of angles in the joints of the lower limbs in the sagittal plane. Moreover, in order to achieve the objective of the work, the following descriptive statistical methods were used: mean, standard deviation, minimum and maximum values, variation and Shapiro-Wilk test.

\section{RESULTS}

\section{Kinematics and kinetics parameters}

Figures 1-3 illustrate changes in the kinematics and kinetics parameters in the stand-to-sit-to-stand motion recorded during the examination of 1 person that participated in the study. In the study group, shapes of the curves were similar to those presented in Figures 1-3.

In the study group, the smallest ranges of angles in the sagittal plane were observed for the ankle joint (from $0.8^{\circ}$ to $26^{\circ}$ ). The values of angles in the knee and hip joints depend on the length of lower limbs with respect to the chair. For the knee joint, the extreme values ranged from $-7.5^{\circ}$ to $100.6^{\circ}$, whereas for the hip joint they were from $5.6^{\circ}$ to $89^{\circ}$. In the coronal plane, the values for the ankle joint ranged from 0 to $7^{\circ}$, in the transverse plane they were $-33^{\circ}$ to $1^{\circ}$. The angle in the knee joint reached the values from $-2^{\circ}$ to $44.7^{\circ}$ in the coronal plane and from $-34^{\circ}$ to $27.5^{\circ}$ in the transverse plane. In the hip joint, the angles were, respectively, from $-9^{\circ}$ to $0.3^{\circ}$ and from $20^{\circ}$ to $42^{\circ}$. The obtained values of the angles have the biggest ranges (in the descending order) in the sagittal, transverse and coronal planes. The difference between the maximum and the minimum value for the sagittal plane reaches ca. $100^{\circ}$ for the
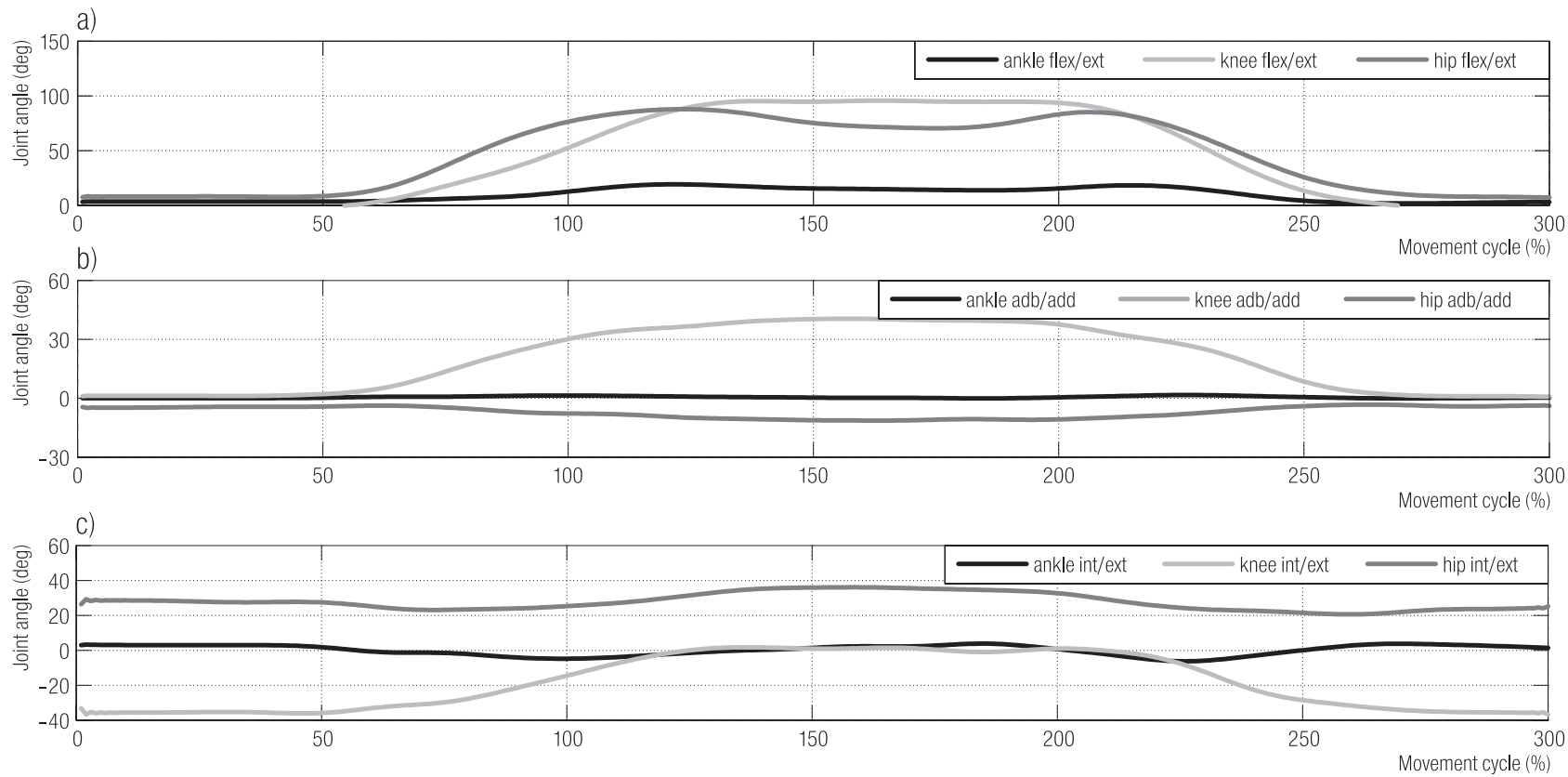

flex/ext - flexion/extension; adb/add - abduction/adduction; int/ext - internal/external rotation.

Fig. 1. Angular changes in the joints of the lower limb during the stand-to-sit-to-stand movement for 1 subject: a) in the sagittal plane, b) in the coronal plane, c) in the transverse plane 


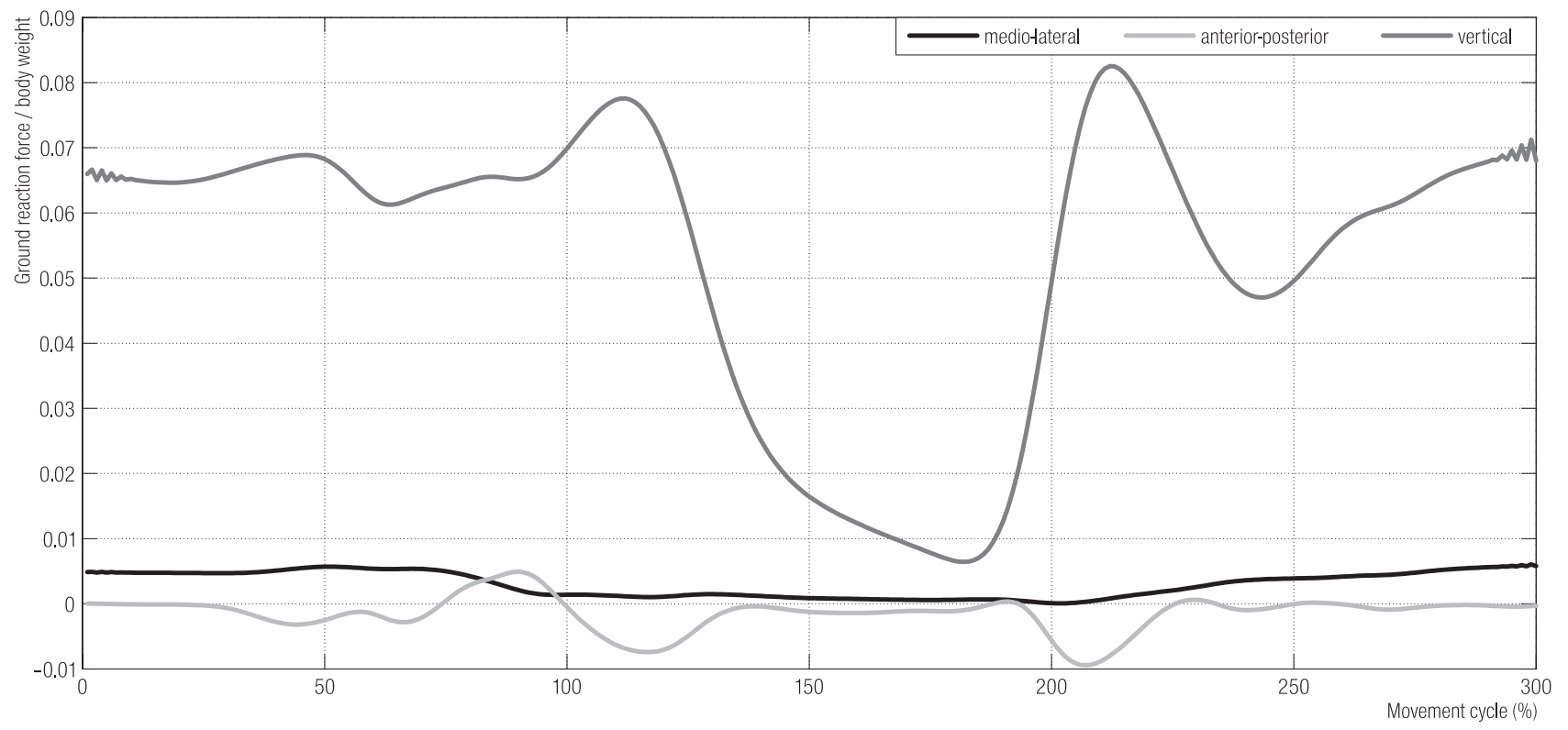

Fig. 2. Components of ground reaction forces for 1 subject
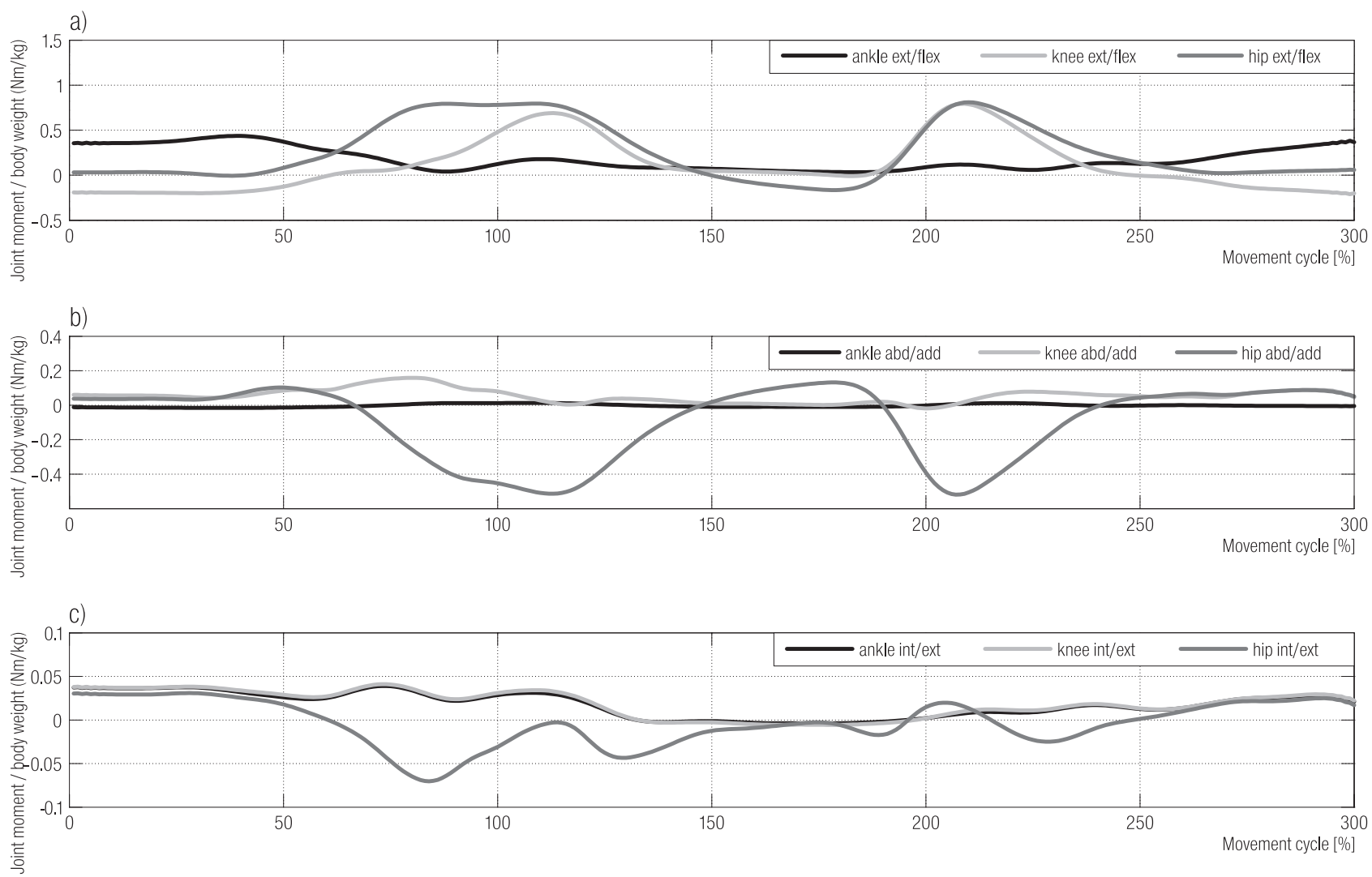

Abbreviations as in Figure 1.

Fig. 3. Muscle torques in the lower limb joints for 1 subject: a) in the sagittal plane, b) in the coronal plane, c) in the transverse plane 
knee and hip joints and $25^{\circ}$ for the ankle joint. These results might suggest that in the case of limitation of the mobility in joints, the biggest problems in performing the stand-to-sitto-stand movement will be noticeable in the sagittal plane. The biggest values of ground reaction forces normalized for body weight are reached for the vertical component (Figure 2) within the range from: 0 to 0.08 . Anterior-posterior and lateral-medial components range, respectively, from -0.005 to 0.007 and from -0.007 to 0.005 . Similarly to the angles, the obtained results have big ranges of values in the sagittal plane. The differences between the maximum and the minimum value for the anteriorposterior and lateral-medial components equal in both cases 0.012 and this value is by 7 times lower than the vertical component.

The charts for the muscle torques that act on the joints in the lower limbs, normalized for body mass, are presented in Figure 3. For the ankle joint, the minimum value in the studied group in the sagittal plane was $0.3 \mathrm{Nm} / \mathrm{kg}$, whereas the maximum one was: $0.9 \mathrm{Nm} / \mathrm{kg}$. For the knee joint, the values ranged from -0.3 to $0.8 \mathrm{Nm} / \mathrm{kg}$, whereas for the hip joint they were from -0.05 to $0.5 \mathrm{Nm} / \mathrm{kg}$. In the coronal and transverse planes, the respective values for the ankle joint ranged from -0.5 to $0.3 \mathrm{Nm} / \mathrm{kg}$ and from -0.2 to $0.3 \mathrm{Nm} / \mathrm{kg}$. In the knee joint, the values ranged from -0.1 to $0.3 \mathrm{Nm} / \mathrm{kg}$ and from -0.02 to $0.2 \mathrm{Nm} / \mathrm{kg}$. In the hip joint: from -0.04 to $0.1 \mathrm{Nm} / \mathrm{kg}$ and from -0.02 to $0.2 \mathrm{Nm} / \mathrm{kg}$. The muscle torques reached the highest values (in the descending order) in the ankle, knee and hip joints in all the 3 planes. Similarly to the previous parameters, the biggest differences between the maximum and minimum values observed in the sagittal plane were $1.2 \mathrm{Nm} / \mathrm{kg}$ (ankle joint), $1.1 \mathrm{Nm} / \mathrm{kg}$ (knee joint) and $0.5 \mathrm{Nm} / \mathrm{kg}$ (hip joint).

\section{Determination of the phases}

\section{in the stand-to-sit-to-stand task}

Using the Shapiro-Wilk test we determined that the distribution of the symmetry indices $\mathrm{S}_{\text {joint, }}^{\mathrm{p}}$ for all the parameters analyzed in the 3 planes was significantly different than the normal distribution $(p=0.001)$. The strongest asymmetry was observed in the transverse plane and the smallest was found in the sagittal plane. In order to determine the phases during the analyzed movement, the authors calculated the variance of indices $\mathrm{SI}_{\text {joint, }}^{\mathrm{p}}$ for all the analyzed variables. The highest variance was found for abduction and adduction movements in the ankle joint $\left(\sigma^{2}=0.1644\right)$, whereas the lowest variance was observed for flexion and extension in the hip joint $\left(\sigma^{2}=0.0048\right)$. A small variance was also found for $\mathrm{SI}_{\text {joint, }}^{\mathrm{p}}$ calculated for the vertical component of ground reaction forces $\left(\sigma^{2}=0.0119\right)$ and for the angle in the knee joint $\left(\sigma^{2}=0.0138\right)$.

In order to determine phases in the stand-to-sit-to-stand cycle, the parameter which was characterized by the lowest variance calculated for the symmetry index SI $I_{\text {joint, }}^{\text {p }}$ was taken into consideration (flexion and extension in the hip joint). A derivative was calculated for this parameter, thus obtaining an angular velocity profile. The local minimums and maximums represented the boundaries of phases in the stand-to-sit-to-stand movement.

The phases of sitting down and rising (Figure 4) from the chair are composed of the following stages:

I. $\left(0, \mathrm{v}_{1}{ }^{\mathrm{max}}\right)$ - the phase of preparation before sitting down: the subject is standing still, all joints are fully extended. The movement starts from flexion in the joints of the lower limb and from increasing the mean velocity obtained in the group, from zero to $218.48 \mathrm{deg} / \mathrm{s}$. The mean minimum and maximum values of the angles in the sagittal plane for the ankle joint range from $2.03^{\circ}$ to $10.8^{\circ}$; for the knee joint: from $-6.94^{\circ}$ to $23.9^{\circ}$, and, for the hip joint: from $-5.15^{\circ}$ to $16.09^{\circ}$.

II. $\left(\mathrm{v}_{1}{ }^{\max }, \mathrm{v}_{1}{ }^{\mathrm{min}}\right)$ - the phase of sitting down: it represents a transition to the phase of sitting. The angular velocity starts to decrease to the negative value of $-74.42 \mathrm{deg} / \mathrm{s}$ (Figure 4). The values of the angles in all the joints are increased and range as follows: $11.10-23.49^{\circ}$ (ankle), 25.58-97.34 (knee), and 13.09-40.50 (hip). 


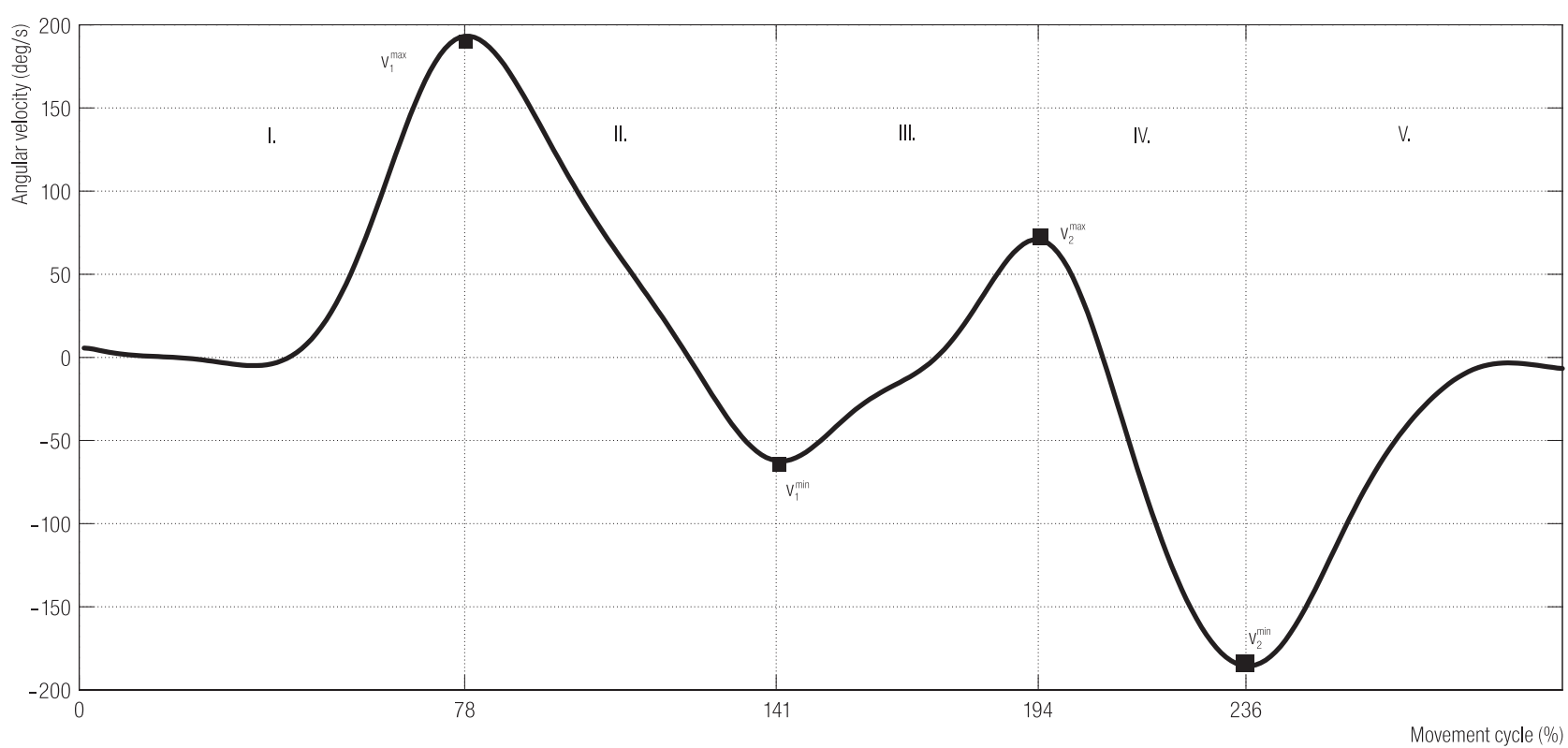

I - standing, initial flexion in the knee joint and the hip joint; II - sitting down phase; III - sitting; IV - rising to standing; V - final flexion in the knee and the hip joints - standing.

Fig. 4. Determination of the phases for the stand-to-sit-to-stand task based on the angular velocity in the hip joint

III. $\left(\mathrm{v}_{1}{ }^{\mathrm{min}}, \mathrm{v}_{2}{ }^{\mathrm{max}}\right)$ - the phase of sitting - it is the point when the subject is in a quiet sitting position. The values of the angles remain at one level: $15.01-18.51^{\circ}$ (ankle), 95.44-97.61 (knee) and 26.63-33.71 ${ }^{\circ}$ (hip). Mean value of the velocity changes from the negative one of -75.7 to $88.4 \mathrm{deg} / \mathrm{s}$.

IV. $\left(\mathrm{v}_{2}{ }^{\mathrm{max}}, \mathrm{v}_{2}{ }^{\mathrm{min}}\right)$ - the phase of rising to standing - it is the point when the subject, from the quiet sitting position, starts the first movement - the trunk begins to lean forward. The values of the angles range, respectively, from $23.25^{\circ}$ to $15.89^{\circ}$ (ankle), from $96.98^{\circ}$ to $37.91^{\circ}$ (knee), and from $40.46^{\circ}$ to $17.52^{\circ}$ (hip). The values of velocity change from the minimum level of 106.45 $\mathrm{deg} / \mathrm{s}$ to the negative value of $-215.56 \mathrm{deg} / \mathrm{s}$.

$\mathrm{V}$. $\left(\mathrm{v}_{2}{ }^{\mathrm{min}}, 0\right)$ - the final phase - it is the point when the standing position is reached, even if it is not a stable condition. The values of angles decrease with respect to those from the phase IV: $16.12^{\circ}$ to $-2.78^{\circ}$ (an$\mathrm{kle}$ ), $35.93^{\circ}$ to $-5.37^{\circ}$ (knee), $20.36^{\circ}$ to $-6.51^{\circ}$ (hip), whereas the velocity rises from $-215.09 \mathrm{deg} / \mathrm{s}$ to $0 \mathrm{deg} / \mathrm{s}$.

\section{Analysis of the differences between the parameters and the dynamic symmetry index in the stand-to-sit-to-stand task}

In order to solve the problem whether the task of standing up can be considered as a reverse task with respect to sitting down in terms of the analyzed kinetic and kinematic variables and 3 components of ground reaction forces, the analysis in Figure 5 presents the differences in symmetry indices SImod between phases I and V and between phases II and IV.

The highest values of asymmetry occur in the phase of the relaxed sitting for ground reaction forces, which is reflected in muscle torques in the lower limb joints. This is caused by uneven load in lower limbs during relaxed sitting. The negative values shown in Figure 5 indicate the higher value of the SImod index for the task of standing up.

In phases I and V, which mark the beginning and end, low SImod values were found, which causes that the differences are insignificant. The biggest differences were observed in the sitting down and standing up tasks. The 


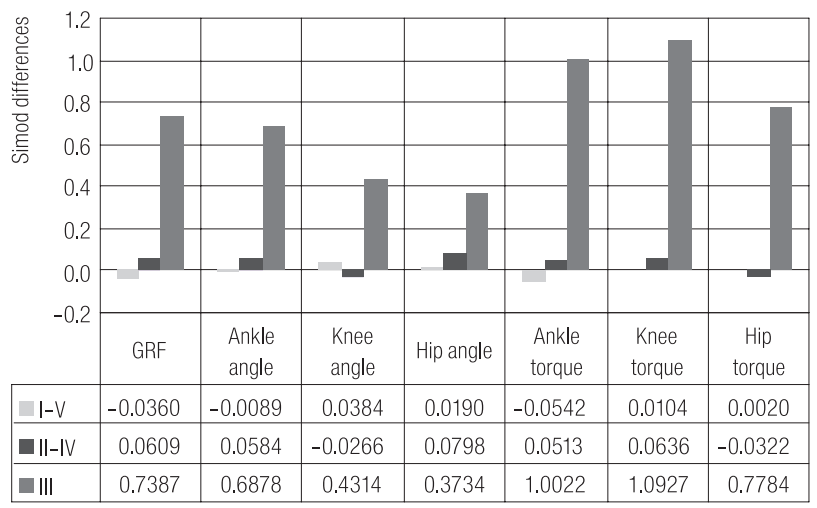

GRF - ground reaction force.

Fig. 5. Differences between phases I and $\mathrm{V}$ and between phases II and IV in symmetry indices SImod and values of SImod in phase III for all the variables

biggest differences in angles were found, in the descending order, in the hip joint, the ankle joint and the knee joint, whereas the order in the case of muscle torques is as follows: the knee joint, the ankle joint and the hip joint. The results obtained in the study suggest that evaluation of the stand-to-sit-to-stand task based on the differences between the phases I and $\mathrm{V}$ and between the phases II and IV for the SImod index are close to 0 for the kinematic and kinetic parameters. The results discussed above supported the results obtained for the dynamic symmetry index. Only the symmetry indices calculated for the kinematic parameters in the sagittal plane were taken into consideration since they represented the dynamics of changes (Figure 6).

Figure 6 presents changes in the dynamics of the kinematic parameters of the movement. The main areas which are susceptible to changes are phases I and II and phases IV and V. In phase III of the relaxed sitting, $\operatorname{DSI}(t) \approx 0$. When comparing the differences in the maximum values of DSI $(\mathrm{t})$ obtained for the areas I and II and in the areas IV and $\mathrm{V}$, the value of $\operatorname{DSI}(\mathrm{t}) \approx 0$ is obtained, which suggests that the standing up task in healthy subjects is a reverse task in terms of the symmetry of the analyzed parameters.

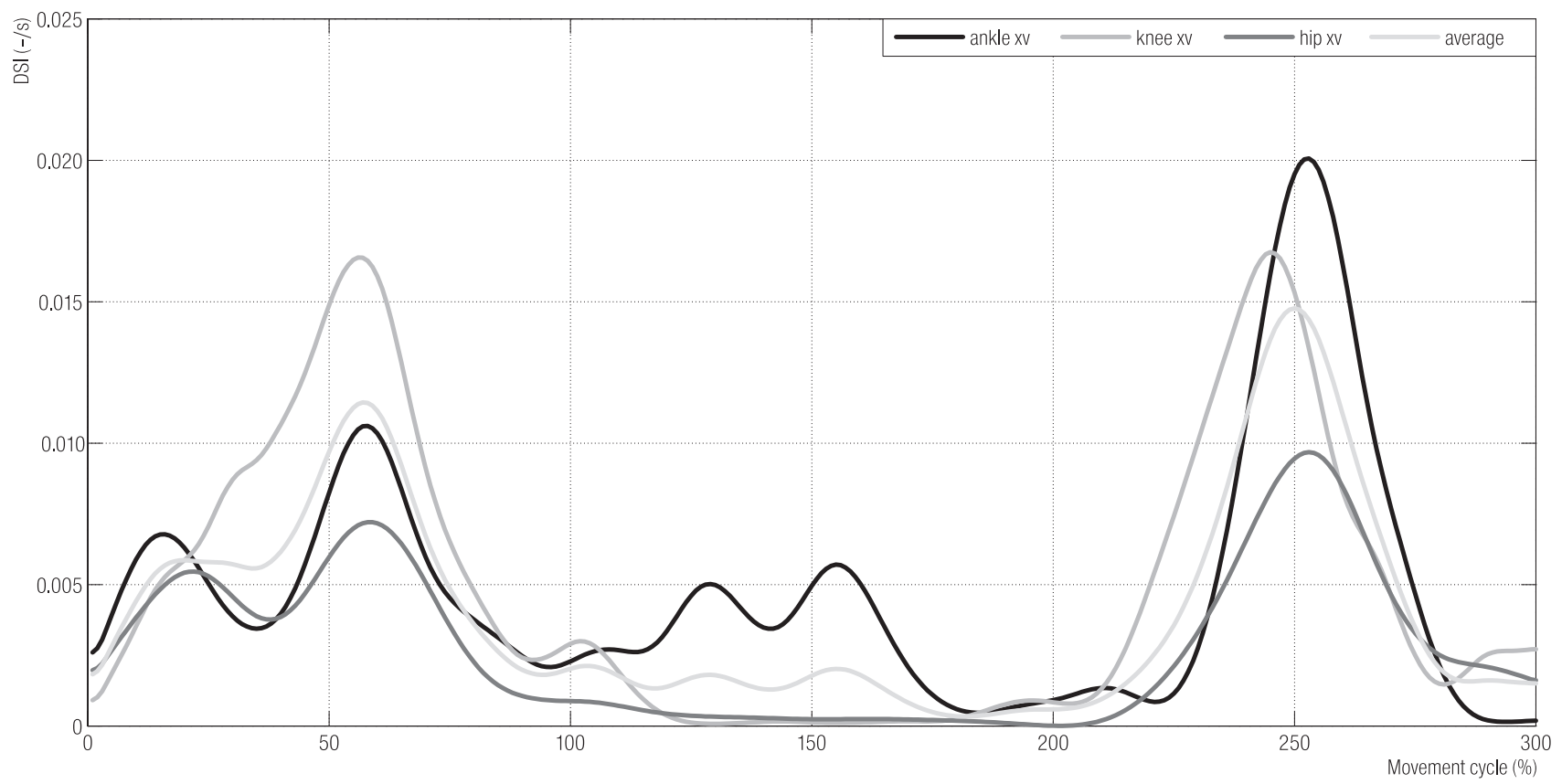

$\mathrm{XV}$ - symmetry derivative indices calculated for kinematic parameters for a given joint in the sagittal plane.

Fig. 6. Dynamics of changes in the symmetry index (DSI) for kinematic parameters in the sagittal plane 


\section{DISCUSSION}

Common abilities of daily living include the ability to sit down from a standing position and rise from a seated position [10]. This activity requires an adequate postural control during the motor transfer from a stable 2-point base (the standing position) to a 3-point base (the sitting position) and again to a 2-point base. Therefore, many studies have attempted to provide a biomechanical description of the stand-to-sit or sit-to-stand tasks by applying commonly accepted data collection methodologies such as the 3-dimensional kinematics and kinetics analysis.

\section{Kinematics and kinetics parameters}

A number of authors [11-13] have emphasized that a disturbed activity in the muscles of lower limbs, particularly the lack of balance in their activity (some groups are weakened while others show contractures), causes a disturbance in the proper movement trajectory, which consequently leads to the patellofemoral pain syndrome. This syndrome is characterized by pain or discomfort seemingly originating from the contact of the posterior surface of the patella with the femur. The cause of pain and dysfunction often results from either abnormal forces or prolonged repetitive compressive or shearing forces on the joint. The result is thinning and softening of the articular cartilage under the patella, inflammation and subchondral bony changes in the distal femur or patella.

Typically, patients will complain of localized anterior knee pain, which is exacerbated by sports, walking, stair climbing, or sitting for a long time. The pain from prolonged sitting is thought to occur because of the constant pull of the quadriceps muscle on the knee cap while sitting, which causes its impaction against the hard and unyielding surfaces of the bones of the knee joint.

The patellofemoral pain syndrome is a condition where treatment procedures should be focused in particular on gait retraining through improvement in the mobility of the lower limb, which might reduce pain and improve the function of the knee joint. Therefore, the results obtained in this study might be used for comparison and assessment of the stand-to-sit-to-stand movement in people with disordered mechanics and asymmetry of this movement.

The obtained values of the angles have the biggest ranges (in the descending order) in the sagittal, transverse and coronal planes. The difference between the maximum and the minimum value for the sagittal plane reaches ca. $100^{\circ}$ for the knee and hip joints and $25^{\circ}$ for the ankle joint. The ranges of motion in the sagittal plane are the biggest, but it seems that the strongest effect on the lower limb mechanics comes from the ranges of internal rotation and adduction in the hip joint. When performing the stand-to-sit movement, an increased internal rotation and adduction in the hip joints can be observed and the knee joints are bent inwards, which forces a compensatory rotation of the leg shank to the outside and, consequently, disturbs the whole mechanics of the lower limb. The retraining of movements and the necessity of control of internal rotation in the hip joint in the people with the patellofemoral pain syndrome have already been emphasized [12]. Similarly to the previous parameters, the biggest differences between the maximum and the minimum values observed in the sagittal plane were $1.2 \mathrm{Nm} / \mathrm{kg}$ (ankle joint), $1.1 \mathrm{Nm} / \mathrm{kg}$ (knee joint) and $0.5 \mathrm{Nm} / \mathrm{kg}$ (hip joint).

The kinematics and kinetics analyses of stand-to-sit-tostand carried out in this paper will help evaluate the differences between the population of the healthy and the disabled persons. The results are consistent with those obtained in the past by other authors $[14,15]$. Furthermore, Yoshioka et al. (2007) [15] found the minimum peak joint moment at which people are able to stand up from a chair. In order for a model with a stature of $1.74 \mathrm{~m}$ to successfully stand up from a chair with the height of $0.40 \mathrm{~m}$, the minimum peak joint moments of $0.24,0.51$ and $0.02 \mathrm{Nm} / \mathrm{kg}$ are required at the hip, knee and ankle joints, respectively. 


\section{Symmetry calculation method}

\section{and identification of phases}

Symmetry has been defined as "perfect agreement of the external kinetics and kinematics of the left and right leg" [16]. Sadeghi et al. [17] suggest that symmetry is achieved if no statistical differences exist between parameters that are measured bilaterally. The SI index is the most commonly used and cited one in the publications on symmetry analysis and indicates full symmetry when SI $=0$, while SI $\geq 100 \%$ indicates its absence. In the present paper, SI and its variations were a way to determine the parameter on the basis of which it was possible to identify stand-to-sit and sit-to-stand movement phases.

The stand-to-sit and sit-to-stand movement cycle could benefit from a similar approach to that used to define the gait cycle, but only 2 studies [10,18] have attempted to establish a definitive framework within which the standto-sit and sit-to-stand movements can be analyzed. Kralj et al. [10] presented a formal definition of human standing up and sitting down movements based on the sagittal plane goniometric and force plate data from 20 normal subjects. This definition consisted of defined characteristic events selected on changes in ground reaction forces and relative time intervals between them. Kerr et al. [18] distinguished 14 phases for the entire movement cycle: 7 for the descending and 7 for the rising phase based on the linear displacement and acceleration of the trunk and angular displacement of the knee (Table 1).
In the literature, we can find analyses of the stand-to-sitto-stand movement, which have been conducted mostly in healthy subjects $[19,20]$. Only a few studies have been devoted to pathological subjects [21-23]. The above-mentioned studies distinguished from 2 to 5 phases based on various kinematics or kinetics parameters. For example, Schenkman et al. [3] presented a body analysis of rising from a chair in 9 healthy subjects. The authors described 4 phases of this activity based on various data obtained from the experiment. Phase I is flexion - the momentum phase used to generate the initial momentum for rising. Phase II begins as the individual leaves the chair seat and ends at maximal ankle dorsiflexion. The forward momentum of the upper body is transferred to the forward and upward momentum of the total body. Phase III is an extension phase when the body rises to its fully upright position. Phase IV is a stabilization phase. The phases presented were differentiated in terms of the momentum and stability characteristics.

It can be observed that each stand-to-sit-to-stand movement cycle in our study is comprised of 2 phases: a descending phase, when a subject descended from the standing to the seated position, and a rising phase, when the subject rose from the seated to the standing position. These 2 phases are discrete, i.e., not continuous as in the gait cycle. The descending phase depends on the eccentric muscle work responsible for extension and flexion of the feet (the phase which inhibits the effect of the moment of gravitational forces), whereas the rising phase is a concentric action

Table 1. Descending and rising phases during a sit-stand-sit movement cycle [18]

\begin{tabular}{ll}
\hline \multicolumn{1}{c}{ Descending phase } & \multicolumn{1}{c}{ Rising phase } \\
\hline Initiation of forward lean & Initiation of forward lean \\
Initiation of knee flexion & Initiation of knee extension \\
Initiation of vertical displacement & Initiation of vertical displacement \\
Final forward lean & Final forward lean \\
Final knee flexion & Final vertical displacement \\
Final vertical displacement & Final knee extension \\
Final backward lean (recovery) & Final backward lean (recovery) \\
\hline
\end{tabular}


of these muscles when the muscles are lifting the body up to the upright position. If these muscles are weakened, the lower limbs are improperly positioned. There is no description in the literature regarding the most efficient way to perform squat exercises in order to promote balanced activation of the dynamic stabilizers of the patella and higher electrical activity of the pelvic stabilizers [24].

Furthermore, there is no information in the available literature to allow authors to select the parameters used for the division into phases. It seems that the present study is the only one that has discussed the above-mentioned problem. Furthermore, the analyzed group was uniform in terms of age. All subjects were 22 years old. Thus, the normality and efficiency of the movement have been identified without the influence of ageing, which suggests that, similar to human gait, strategies of rising from a chair might also differ [18].

Other studies have found that the elderly demonstrate greater forward lean of the trunk, perform the activity of rising more slowly, and adopt different strategies in performing the activity of rising [25]. Furthermore, no differences were found in the group of the healthy people analyzed in the study between the problem of sitting down and standing up from the chair in terms of the parameters discussed. This leads to the conclusion that these are reversed actions. With an assumption of bilateral symmetry, functionally important information regarding the peak moments at the knee and hip for individuals performing the sit-to-stand movement may be lost [26].

Better understanding of the movement of sitting down and standing up has clear implications for clinical practice and environmental health in the assessment and rehabilitation of clinical conditions such as stroke and Parkinson's disease. Moreover, the stand-to-sit-to-stand movement is a functional task which is very important in elderly subjects. Its decline with ageing accentuates the risk of falls and represents a factor contributing to the loss of autonomy. Knowledge of the movement phases of the sitting down and standing up task in young healthy persons is a database that allows making comparisons to the results obtained for the elderly or disabled. It may be useful for doctors, therapists and a variety of populations with reduced strength and/or mobility.

\section{REFERENCES}

1. Biscarini A, Benvenuti P, Botti F, Mastrandrea F, Zanuso S. Modelling the joint torques and loading during squatting at the Smith machine. J Sports Sci. 2011;29(5):457-69, http:// dx.doi.org/10.1080/02640414.2010.534859.

2. Roebroek M, Doorenbosch CA, Harlaar J, Jacobs R, Lankhorst G. Biomechanics and muscular activity during sit-tostand transfer. Clin Biomech. 1994;9(4):235-44, http://dx.doi. org/10.1016/0268-0033(94)90004-3.

3. Schenkman M, Berger R, Riley P, Mann R, Hodge W. Whole-body movements during rising to standing from sitting. Phys Ther. 1990;70(10):638-48.

4. Hirschfeld H, Thorsteinsdottir M, Olsson E. Coordinated ground forces exerted by buttocks and feet are adequately programmed for weight transfer during sit-to-stand. J Neurophysiol. 1989;82(6):3021-9.

5. Roy G, Nadeau S, Gravel D, Piotte F, Malouin F, McFadyen B. Side difference in the hip and knee joint moments during sit-to-stand and stand-to-sit tasks in individuals with hemiparesis. Clin Biomech. 2007;22(7):795-804, http://dx.doi. org/10.1016/j.clinbiomech.2007.03.007.

6. Song G, Yuan H, Tang Y, Song Q, Ge Y. A novel three-axis force sensor for advanced training of shot-put athletes. Sensors Actuators A: Physical. 2006;128(1):60-5, http://dx.doi. org/10.1016/j.sna.2006.01.016.

7. Chow J, Kuenster A, Lim Y. Kinematics analysis of javelin throw performed by wheelchair athletes of different functional classes. J Sports Sci Med. 2003;2:36-46.

8. Wagner H, Pfusterschmied J, von Duvillard S, Müller E. Performance and kinematics of various throwing techniques in team-handball. J Sports Sci Med. 2011;10:73-80. 
9. Winter DA. Biomechanics and motor control of human movement. 2nd ed. New York: John Wiley Sons Inc; 1990.

10. Kralj A, Jaeger RJ, Munih M. Analysis of standing up and sitting down in humans: Definitions and normative data presentation. J Biomech. 1990;23(11):1123-38, http://dx.doi. org/10.1016/0021-9290(90)90005-N.

11. Smith D. Assessing patellofemoral pain dysfunction: Utilising a kinematic paradigm. Sportex Med. 2012;52:12-8.

12. Souza R, Draper C, Fredericson M, Powers C. Femur rotation and patellofemoral joint kinematics: A weight-bearing magnetic resonance imaging analysis. J Orthop Sports Phys Ther. 2010;40(5):277-85, http://dx.doi.org/10.2519/ jospt.2010.3215.

13. Macrum E, Bell D, Boling M, Lewek M, Padua D. Effect of limiting ankle-dorsiflexion range of motion on lower extremity kinematics and muscle-activation patterns during a squat. J Sport Rehabil. 2012;21(2):144-50, http://dx.doi.org/ S0966-6362(13)00116-1.

14. Highsmith MJ, Kahle JT, Carey SL, Lura DJ, Dubey RV, Csavina KR, et al. Kinetic asymmetry in transfemoral amputees while performing sit to stand and stand to sit movements. Gait Posture. 2011;34(1):86-91, http://dx.doi. org/10.1016/j.gaitpost.2011.03.018.

15. Yoshioka S, Nagano A, Himeno R, Fukashiro S. Computation of the kinematics and the minimum peak joint moments of sit-to-stand movements. Biomed Eng OnLine. 2007;6(26): 1-14, http://dx.doi.org/10.1186/1475-925X-6-26.

16. Herzog W, Nigg B, Read L, Olsson E. Asymmetries in ground reaction force patterns in normal human gait. Med Sci Sports Exerc. 1989;21(1):110-4, http://dx.doi. org/10.1249/00005768-198902000-00020.

17. Sadeghi H, Allard P, Prince F, Labelle H. Symmetry and limb dominance in able-bodied gait: A review. Gait Posture. 2000;12(1):34-45, http://dx.doi.org/10.1016/S0966-6362 (00)00070-9.
18. Kerr KM, White JA, Barr DA, Mollan RA. Standardisation and definitions of the sit-stand-sit movement cycle. Gait Posture. 1994;2(3):182-90, http://dx.doi.org/10.1016/09666362(94)90006-X.

19. Lindemann U, Claus H, Stuber M, Augat P, Muche R, Nikolaus T, et al. Measuring power during the sit-to-stand transfer. Eur J Appl Physiol. 2003;89(5):466-70, http://dx.doi. org/10.1007/s00421-003-0837-z.

20. Khemlani MM, Carr JH, Crosbie WJ. Muscle synergies and joint linkages in sit-to-stand under two initial foot positions. Clin Biomech. 1999;14(4):236-46, http://dx.doi.org/10.1016/ S0268-0033(98)00072-2.

21. Park ES, Park C, Lee HJ, Kim DY, Lee DS, Cho SR. The characteristics of sit-to-stand transfer in young children with spastic cerebral palsy based on kinematic and kinetic data. Gait Posture. 2003;17(1):43-9, http://dx.doi.org/10.1016/ S0966-6362(02)00055-3.

22. Su FC, Lai KA, Hong WH. Rising from chair after total knee arthroplasty. Clin Biomech. 1998;13(3):176-81, http:// dx.doi.org/10.1016/S0268-0033(97)00039-9.

23. Hesse S, Schauer M, Malezic M, Jahnke M, Mauritz KH. Quantitative analysis of rising from a chair in healthy and hemiparetic subjects. Scand J Rehabil Med. 1994;26(3):161-6.

24. Felício L, Dias L, Silva A, Oliveir A, Bevilaqua-Grossi D. Muscular activity of patella and hip stabilizers of healthy subjects during squat exercises. Braz J Phys Ther. 2011;15(3): 206-11, http://dx.doi.org/10.1590/S1413-35552011000300006.

25. Kerr KM, White JA, Barr DA, Mollan RA. Analysis of the sit-stand-sit movement cycle in normal subjects. Clin Biomech. 1997;12(4):236-45, http://dx.doi.org/10.1016/S02680033(96)00077-0.

26. Lundin TM, Grabiner MD, Jahnigen DW. On the assumption of bilateral lower extremity joint moment symmetry during the sit-to-stand task. J Biomech. 1995;28(1):109-12, http://dx.doi.org/10.1016/0021-9290(95)80013-1.

This work is available in Open Access model and licensed under a Creative Commons Attribution-NonCommercial 3.0 Poland License - http://creativecommons.org/ licenses/by-nc/3.0/pl/deed.en. 